\title{
Comment on
}

\section{"Global risk of radioactive fallout after major nuclear reactor accidents" by Lelieveld et al. (2012)}

\author{
J. Lelieveld ${ }^{1,2}$, M. G. Lawrence ${ }^{1, *}$, and D. Kunkel ${ }^{1}$ \\ ${ }^{1}$ Max Planck Institute for Chemistry, P.O. Box 3060, 55020 Mainz, Germany \\ ${ }^{2}$ The Cyprus Institute, Nicosia, Cyprus \\ * now at: Institute for Advanced Sustainability Studies e.V., Berliner Straße 130, 14467 Potsdam, Germany \\ Correspondence to: J. Lelieveld (jos.lelieveld@ mpic.de)
}

Received: 26 June 2012 - Published in Atmos. Chem. Phys. Discuss.: 3 August 2012

Revised: 14 October 2012 - Accepted: 21 November 2012 - Published: 3 January 2013

In the above mentioned article we assessed the worldwide risk of exposure to radioactivity due to the atmospheric dispersion of gases and particles following severe nuclear accidents, using particulate ${ }^{137} \mathrm{Cs}$ and gaseous ${ }^{131} \mathrm{I}$ as proxies for the fallout. To evaluate the global risks, we applied empirical evidence to estimate the probability of severe accidents. Our results and the methods used have been subject of scientific and public debate. For this reason, we re-opened the discussion and offered the possibility to contribute comments. We used Atmospheric Chemistry and Physics Discussions as a transparent, public and archived forum, through the submission of a standard "peer-reviewed commentary", which is directly linked to the original scientific publication. Commentaries, clarifications and corrections of this nature are a standard procedure in other journals, although most do not require peer review of such commentaries as in ACP; we note that this is not, as asserted in some of the comments, a submission intended as a new scientific publication. We have also used the opportunity of this forum to provide some additional information and explanation about the assumptions and methods basic to our work.

Answers to frequently asked questions about this article:

Q1. Why did you adopt the Chernobyl accident as a source of radioactivity in your model?

The Chernobyl accident was at the time of our manuscript's publication (and is still) the only INES 7 accident for which a broad consensus exists about the emissions. The emissions by Chernobyl have been adopted in many previous publications and were presented as "revised estimates" by IAEA (2006). Furthermore, Davoine and Bocqet (2007) re-assessed the Chernobyl source term by inverse modeling and found that their results are in good agreement with the latest reported emission estimates with only a minor difference in their temporal representation. Nevertheless, it may be assumed that substantial uncertainties remain. We only used ${ }^{131}$ I and ${ }^{137} \mathrm{Cs}$ sources from Chernobyl, as these isotopes are typically emitted from any type of nuclear reactor after a major accident. For the other reactors accounted for in our global model the emissions were scaled by their gross capacity to account for the different amounts of nuclear fuel.

\section{Q2. Why didn't you adopt Fukushima as a source of radioactivity in your model?}

The emissions from Fukushima are associated with a significant degree of uncertainty, and are subject of scientific debate. Nevertheless, the order of magnitude of the Fukushima emissions is meanwhile reasonably well known, at least for certain species, indicating that they are generally lower than from Chernobyl. Table 1 in our article presents a range of emissions based on the two references available at the time of publication, Chino et al. (2011) and Stohl et al. (2012). If the Fukushima emissions per reactor would be a factor of ten less than of Chernobyl, and if they would also be more representative for major accidents than Chernobyl, the calculated risk 
of contamination would decrease proportionally by a factor of ten. On the other hand, there are several countering factors which make our estimates of the contamination risk likely to be underestimates, including the increased modern threat due to terrorism, and the ageing fleet of operational nuclear power plants, as well as the contamination due to other radionuclides (see Q4).

Q3. Why were only Chernobyl and Fukushima considered in the estimate of the number of major accidents, and not less severe accidents such as Three Mile Island?

We concentrate on INES 7 events associated with the major release of radioactive material, which are by definition "major accidents" (INES is the International Nuclear Event Scale). Although the other accidents also released radioactivity, the amounts were much smaller (see Table 1 in our article). By leaving them out, we arrive at a more conservative estimate.

\section{Q4. How is "contaminated" by radioactivity defined?}

We adopt the deposition of $\geq 40 \mathrm{kBq} \mathrm{m}^{-2}$ as contaminated, following the definition given by the IAEA (2005). Note that this refers to deposition on the ground, not radiation doses (expressed in Sv). We applied the $\geq 40 \mathrm{kBq} \mathrm{m}^{-2}$ only to the deposition of ${ }^{137} \mathrm{Cs}$, following the literature. However, IAEA (2005) defines contamination based on this threshold for all gamma and beta radiating substances. Thus this is a discrepancy in the literature that needs to be resolved. If we would apply this definition of IAEA (2005) strictly, we would have to add the deposition of substances such as ${ }^{131} \mathrm{I}$ and ${ }^{134} \mathrm{Cs}$, which would increase the calculated risk of contamination accordingly.

\section{Q5. Did you assume that emissions take place only at the surface?}

In the model we emit the radioactive substances by introducing them into the surface layer of about $60 \mathrm{~m}$ depth. We assume that ${ }^{131} \mathrm{I}$ and ${ }^{137} \mathrm{Cs}$ are released gradually and not explosively or by large fires, which would increase the emission height. This assumption leads to a conservative estimate of long-distance transport, which we tested in previous work (Kunkel et al., 2012). In general, the sensitivity to this assumption for the daytime convective boundary layer is small, but for the stable nighttime boundary layer the differences can become more notable.
Q6. Did you use information from non-peer reviewed publications in your model calculations?

We have used the list of reactors worldwide from Wikipedia, as referenced in our article. We have not yet been made aware of specific errors in this listing. From this list we only use two basic parameters, the geographical location and the gross capacity of the reactors, documented in the Supplement. The source strength of radioactivity applied in our model calculations is based on peer-reviewed publications (about Chernobyl), including reports by the International Atomic Energy Agency.

\section{Q7. Have risk assessments of major nuclear accidents been performed previously?}

Yes, in different forms:

a. In 1990 the Nuclear Regulatory Committee (NRC, 1990) reported on the risk of severe nuclear accidents in the USA, associated with reactor core melts (we assume that "severe accident" is equivalent to INES 7) ${ }^{1}$. NRC (1990) mentioned the following: "Of the plants analyzed thus far, most have an estimated likelihood of core melt of between 1 in 10000 and 1 in 100000 per plant year" (NRC, 1990). In the appendix of NRC (1990), which presents the overall risk estimate, only the number of 1 in 10000 is included, being a factor of two larger than the previous estimate by the NRC (1975) of 1 in 20000 , and a factor of two smaller than our current estimate (1 in 5000). The conclusions of the NRC have had important influence worldwide on decisions to approve nuclear reactor technology. In Germany the National Risk Study on Nuclear Power Plants Phase A (GRS, 1980) and Phase B (GRS, 1990) adopted the basic methodology of the NRC and presented similar conclusions about the expected incidence of core melts.

b. For individual reactors a probability risk assessment (PRA) is performed, which is a standard procedure in nuclear engineering; however; the results of PRA's are not available to us (i.e., not publicly available). There are published studies available that present methodologies to perform probabilistic risk assessments of contamination by selected individual nuclear reactor accidents (e.g., Baklanov and Mahura, 2004). However,

\footnotetext{
${ }^{1}$ The INES scale was defined after the Chernobyl accident to inform the public through a standard that can be applied worldwide, agreed upon by the IAEA Parties. The term "severe accident" was defined by the power plant operators/constructors after the Three Mile Island accident on a scale starting from a transient without shutdown of the reactor, an accident with a long shutdown, to a severe accident with core melt (in-vessel or ex-vessel) and closure of the reactor.
} 
none addresses the combined risk of multiple reactors worldwide.

\section{Q8. How do your probability calculations compare with previous work?}

Ideally, we should account for PRA's of individual nuclear reactors worldwide. Since these are not available, we simplify the risk assessment by performing a relative comparison of reactors by adopting a single risk profile, based on empirical information.

a. The appendix of NRC (1990) presents the probability of a core melt of 1 in 10000 per year, and the probability of containment failure 1 in 100 . Based on the four INES 7 events that have actually occurred until 2011, we deduce a frequency of approximately 1 in 5000 per year, which we adopt as the statistically expected value. There are more sophisticated techniques that can be applied to address this, such as that applied by the NRC (1990), which arrived at an estimate of 1 in 10000 . This is only a factor of two different from our estimate of 1 in 5000. If we were to redo our calculations instead using the value directly from the NRC report, our results would decrease by a uniform factor of two everywhere in the deposition intensity and the risk of contamination. In the other direction, a study by Günther et al. (2011) estimates the probability of a core meltdown caused by a terrorist act to be 1 in 1000 per year (in Germany). If we were to apply this estimate uniformly (thus not even accounting for other risks) the calculated risk of contamination would increase by a factor of five.

b. The NRC (1990) also made further assumptions, such as the probability of full containment after a meltdown being $99 \%$, which has not been borne out historically. In fact, the probability estimate of a major release of radioactivity by NRC (1990), being a combination of 1 in 10000 and the 1 in 100 probability of containment, is 1 in 1000000 . This is 200 times lower than our estimate of 1 in 5000. NRC (1990) furthermore assumed a $90 \%$ probability for winds being in a "favorable direction" for evacuation, and a $90 \%$ probability of not having an inversion layer, neither of which is applicable to our analysis of the overall deposition and the risk of contamination, since we integrate the results globally in all directions and with an appropriate model-based weighting for all meteorological conditions that occur over a year. Finally, NRC (1990) assumed a $10 \%$ probability of evacuation failure, which is not relevant for computing the risk of ground contamination.
Q9. Are the factors leading to nuclear reactor accidents independent?

As mentioned in our article, these factors are not necessarily independent. For our calculations we consider the accidents in Fukushima as independent because the reactor safety provisions must be independent. A common cause such as a tsunami or a terrorist act could as well affect reactors farther apart from each other, even in different countries. One must also be aware that three of the 5 active reactor blocks (6 in total) in Fukushima suffered a meltdown, so it would also be incorrect to treat them all as a single unit. We could have also computed the statistics using plants as the unit, rather than reactor blocks, counting Fukushima as a fractional plant meltdown. It is worth noting that NRC (1990) also assumed that reactors are independent; i.e., following the method by NRC (1990) leads to an underestimate of the risk of nuclear power plants with multiple reactors

Q10. Why are the model calculations performed over an entire year, considering that major accidents typically release radioactivity over a much shorter period?

By integrating the model calculated deposition over a year we capture the total contamination by ${ }^{137} \mathrm{Cs}$ over the range of meteorological conditions that might be encountered by an accidental release, which could occur at any time during the year. In reality the emission and deposition occur over a much shorter period. Based on sensitivity simulations we show that the accumulated risk of contamination over longer time periods (e.g., a year) is nearly the same for continuous emissions as the average of the deposition that occurs when emissions take place only over one week, and are then averaged for individual simulations representing all 52 weeks of the year. Thus, we can reduce our model simulation time by a factor of 52, which allows us to reasonably consider the entire set of currently active nuclear reactors worldwide.

The service charges for this open access publication have been covered by the Max Planck Society.

Edited by: R. Harley

\section{References}

Baklanov, A. A. and Mahura, A. G.: Assessment of possible airborne impact from risk sites: methodology for probabilistic atmospheric studies, Atmos. Chem. Phys., 4, 485-495, doi:10.5194/acp-4-485-2004, 2004.

Chino, M., Nakayama, H., Nagai, H., Terada, H., Katata, G., and Yamazawa, H.: Preliminary estimation of the release amounts of ${ }^{131} \mathrm{I}$ and ${ }^{137} \mathrm{Cs}$ accidentally discharged from the Fukushima Daiichi nuclear power plant into the atmosphere, J. Nucl. Sci. Technol., 48, 1129-1134, 2011. 
Davoine, X. and Bocquet, M.: Inverse modelling-based reconstruction of the Chernobyl source term available for long-range transport, Atmos. Chem. Phys., 7, 1549-1564, doi:10.5194/acp-71549-2007, 2007.

Gesellschaft für Reaktorsicherheit (GRS): Deutsche Risikostudie Kernkraftwerke, Eine Untersuchung zu dem durch Störfälle in Kernkraftwerken verursachten Risiko,Verlag TÜV Rheinland, 1980.

Gesellschaft für Reaktorsicherheit (GRS): Deutsche Risikostudie Kernkraftwerke, Phase B, Verlag TÜV Rheinland, 1990.

Günther, B., Karau, K., Kastner E.-M., and Warmuth, W.:Calculating a risk-appropriate insurance premium to cover third-party liability risks that result from operation of nuclear power plants, Versicherungsforen Leipzig, 2011.

International Atomic Energy Agency (IAEA): Regulations for the safe transport of radioactive material, IAEA Safety Standards Series TS-R-1, Vienna, 2005.

International Atomic Energy Agency (IAEA): Environmental Consequences of the Chernobyl Accident and Their Remediation: Twenty Years of Experience, IAEA, Vienna, 2006.
Kunkel, D., Lawrence, M.G., Tost, H., Kerkweg, A., Jöckel, P., and Borrmann, S.: Urban emission hot spots as sources for remote aerosol deposition, Geophys. Res. Lett., 39, L01808, doi:10.1029/2011GL049634, 2012.

Nuclear Regulatory Commission (NRC): Reactor Safety Study An Assessment of Accident Risk in U.S. Commercial Nuclear Power Plants, WASH-1400, NUREG 75/014, 1975.

Nuclear Regulatory Commission (NRC): Severe Accident Risks An Assessment for Five U.S. Nuclear Power Plants, NUREG 1150, 1990.

Stohl, A., Seibert, P., Wotawa, G., Arnold, D., Burkhart, J. F., Eckhardt, S., Tapia, C., Vargas, A., and Yasunari, T. J.: Xenon133 and caesium-137 releases into the atmosphere from the Fukushima Dai-ichi nuclear power plant: determination of the source term, atmospheric dispersion, and deposition, Atmos. Chem. Phys., 12, 2313-2343, doi:10.5194/acp-12-2313-2012, 2012. 